\title{
Estudos iniciais em projetos de arquitetura
}

\author{
José Galbinski'
}

\section{Resumo}

$\mathrm{Na}$ atividade profissional em projetos de Arquitetura pode-se observar que perdura por parte dos jovens uma fase de indecisão, até mesmo de angústia, na passagem do estudo do Programa de Necessidades Ambientais para a da concepção: o dito "susto do papel em branco!". Todos sabem que, em grau moderado, a adrenalina faz parte do chamado processo criativo. No entanto, por vezes, esta passagem é um pouco mais complicada: quando os primeiros esboços do projeto não guardam relação clara com os objetivos a serem atingidos, sendo riscos quase aleatórios. Como se o grafismo pudesse magicamente fornecer a resposta arquitetônica e conduzir ao almejado "partido-geral". Neste artigo, sugere-se uma plataforma de procedimentos a partir da qual aprendizes, ou mesmo jovens arquitetos possam trilhar caminhos que conduzam a resultados satisfatórios. Contrariando a voz corrente, a primeira noção a esclarecer é a de que a concepção arquitetônica, o projeto, não se inicia no chamado Estudo Preliminar, mas sim muito antes.

Palavras-chave: Projeto de arquitetura. Estudo Preliminar. Programa de Necessidades Ambientais.

\section{Introdução}

No cenário das atividades profissionais em projetos de Arquitetura pode ser observado que perdura por parte dos jovens uma fase de indecisão, até mesmo de angústia, na passagem do estudo do Programa de Necessidades Ambientais (PNA) para a da concepção arquitetônica: o dito "susto do papel em branco!”. Por vezes, essa passagem é um pouco mais complicada: quando os primeiros esboços do projeto não guardam relação clara com os objetivos a serem atingidos, sendo riscos quase aleatórios. Como se o grafismo pudesse magicamente fornecer a resposta

1 Arquiteto e Planejador Urbano, PhD pela Cornell University e Coordenador do Curso Arquitetura e Urbanismo - UniCEUB. 
arquitetônica e conduzir ao almejado "partido geral", a solução globalizante da questão posta na prancheta, ou no vídeo do computador. A este respeito vale lembrar Donald A. Schön (2007 p.127) que se expressa de forma dramática, mas otimista:

Não é de surpreender que confusão e mistério reinem nas fases iniciais de um ateliê de projetos. Ainda assim frequentemente, em questão de poucos anos ou mesmo meses, alguns estudantes começam a produzir [...] um design competente [...]

O problema existe precisamente quando o susto, a confusão e o mistério persistem, embora todos saibam que, em grau moderado, a adrenalina faz parte do chamado processo criativo.

Inúmeros são os métodos empregados para a concepção arquitetônica. Alguns deles são intuitivos e difusos, fundados na experiência sensível do arquiteto, outros objetivos e gerais. Enfim, não há consenso nesse campo, nem regra que possa ser adotada universalmente. Ainda assim, cabe ao mestre a obrigação de conduzir o jovem pelos meandros dessa seara de conhecimentos, às vezes contraditórios, por caminhos razoavelmente seguros. A essa questão refere-se Elvan Silva (1986, p. 71) “[...] a doutrina modernista viu-se prejudicada, na esfera do ensino, pelo fato de ter negligenciado um ponto capital, que é a questão do processo projetual." É amplamente reconhecido que o fazer arquitetônico não tem recebido um tratamento conceitual mais aprofundado.

Os "estudos iniciais" aqui apresentados constituem, não uma teoria, mas uma sequência de ações para guiar o início do processo de projetação, que engloba desde a análise do tema até o momento em que o jovem se depara com o dito "papel em branco", isto é, a fase que, supostamente, precede ao projeto propriamente dito.

Todos conhecem a descrição legal ou administrativa das três fases de um projeto: estudo preliminar (EP), anteprojeto (AP) e projeto executivo (PEx). Contrariando a voz corrente, a primeira noção a esclarecer é a de que a concepção arquitetônica, o projeto, não inicia no EP, mas sim muito antes, como adiante se verá. Analisemos desde o começo.

\section{0 tema}

A análise do tema a ser desenvolvido deve abarcar o estudo de sua evolução histórica e significado social. Esta pesquisa é importante na medida 
em que fornece ao projetista visão ampliada da questão a ser abordada e proporciona o conhecimento de como este tema se insere culturalmente na sociedade, bem como suas modificações e permanências no tempo. Mesmo temas aparentemente comuns, como a casa individual, merecem uma reflexão, pois os programas de necessidades têm evoluído em grande velocidade, o que acarreta profundas modificações e torna o conceito de cada tema mais complexo.

\section{Programa de necessidades ambientais (PNA)}

O tema a ser abordado está vinculado diretamente a determinado conjunto de necessidades ambientais. Esse é o vínculo social imediato com que se depara o arquiteto. O estudo do tema deverá ser desdobrado em sua especificidade concreta. Este estudo tem como objetivo a elaboração do Programa de Necessidades Ambientais ou a análise de um programa adrede fornecido, como nos concursos de projetos de arquitetura. O programa arquitetônico de um prédio resume-se em uma listagem comentada de ambientes, mas não determinante da resposta arquitetônica, como bem registra Bernard Tschumi (1994, p. 115):

[...] enough programs managed to function in buildings conceived for entirely different purposes to prove the simple point that there was no necessary causal relationship between function and subsequent form, or between a given building type and a given use.

O tratamento dado ao PNA pelo arquiteto difere da visão meramente normativa ou empreendedorista. Enquanto que esta se preocupa com a viabilidade econômica/funcional, aquela abarca um leque maior de questões, englobando a espacialização, as técnicas construtivas etc. Referindo-se a um texto de Viollet-le-Duc, Afonso C. Martinez (2000, p. 18) escreve que o PNA pode ser considerado confuso inicialmente “[...] não porque aquele que faz a encomenda desconheça suas necessidades, mas porque a enumeração escrita não corresponde à ordem espacial [...]”. O arquiteto colocará ordem no Programa.

Devem-se distinguir cinco maiores partes no PNA, a saber: 


\subsection{Dimensionamentos}

Esta parte tem como base uma matriz de ambientes com seus quantitativos de áreas líquidas/ áreas parciais/ áreas de circulações/ área geral líquida/ área geral bruta de espaços internos/ área geral bruta de espaços externos. $\mathrm{O}$ arquiteto deverá analisar várias possibilidades de configurações espaciais de cada categoria de ambiente, anotando seus impactos no uso, bem como nas áreas. Os primeiros croquis, esquemas parciais, comparecem nessa fase.

\subsection{Características dos usuários}

Esta parte envolve a caracterização dos usuários de cada ambiente: número e frequência de funcionários e de público, horários de atendimento/uso, hierarquia funcional, representatividade, acessibilidade etc.

\subsection{Equipamentos \& mobiliário}

Esta parte envolve a caracterização do mobiliário de cada ambiente: mesas, cadeiras, poltronas, bem como equipamentos: TV, telas de projeção, máquinas etc. $\mathrm{O}$ mobiliário e equipamentos condicionam, em certa medida, as definições formais dos ambientes. Os croquis/esquemas parciais revelam a natureza de cada ambiente, tornando-os mais compreensíveis. De fato, os croquis/esquemas parciais possibilitam uma mais clara apreensão das morfologias ambientais por parte do arquiteto.

\subsection{Relacionamentos de proximidade/afastamento}

Aqui são estudados os vínculos desejáveis entre determinados espaços ou grupo de espaços, bem como distanciamentos que devem ser respeitados. Os primeiros organogramas/fluxogramas parciais ou gerais comparecem nesta fase. É necessário destacar a importância de organogramas parciais, de setores ou grupos de ambientes para o entendimento da intimidade do PNA. 


\subsection{Características ambientais}

Os espaços arrolados no PNA devem ser qualificados quanto às suas necessidades de ventilação, de condicionamento de ar, de exaustão, de tratamento acústico, de isolamento, de grau de iluminação natural/artificial etc.

\section{Orçamento}

A elaboração do PNA possibilita, de imediato, a primeira estimativa de custo da obra. Em seguida, é possível delinear um cronograma de investimentos, determinando o fluxo de recursos que deverão ser alocados ao empreendimento e comparar com a disponibilidade de recursos inicialmente prevista. Esse é um aspecto importante e faz parte do Estudo de Viabilidade, adiante referido.

\section{Estudo de viabilidade (EV)}

O estudo de viabilidade analisa as possibilidades de que a edificação seja efetivamente implantada no sítio face à área geral bruta de espaços internos/ área geral bruta de espaços externos versus às dimensões do terreno, à topografia, à legislação, bem como diante do custo estimado e recursos disponíveis. Este estudo torna-se possível graças aos dados fornecidos pelo PNA.

Um passo adiante é dado quando os estudos são cotejados com levantamentos da demanda. Esse é o caso de projetos de centros comerciais, de redes de lojas, redes de transportes, de hospitais etc. Os estudos de viabilidade, quando levam em conta as características do mercado, são elaborados, via de regra, em conjunto com economistas e planejadores. Nesses estudos são empregadas técnicas de modelagem matemática com dados obtidos dos censos do IBGE e/ou levantamentos de campo. O EV, além disso, determina a dimensão plausível e o grau de complexidade do empreendimento.

No caso dos temas didáticos das escolas de Arquitetura, tais estudos não têm sido desenvolvidos, não por fugirem dos objetivos específicos do ensino, mas pelas limitações de tempo e de pessoal. Aqui, desejamos tão somente, registrar a importância dessa atividade. 


\section{0 lugar}

Não existe arquitetura sem uma intensa implantação física e cultural no sítio. Quer dizer, não existe arquitetura sem seu espaço externo, seja ele urbano ou rural. O ambiente espacial em que se insere uma edificação - o lugar - clama por entendimento, aguardando análise. O lugar fala ao arquiteto. Cabe à sua sensibilidade saber ler e interpretar as características locais, saber distinguir o essencial do supérfluo e levar suas conclusões para a "prancheta". Aldo Rossi (1984, p. 107) elabora o conceito de locus em relação à arquitetura de forma abrangente e didática:

[...] the relation of architecture to its location-the place of artand thereby its connections to, and the precise articulation of, the locus itself as singular artifact determined by its space and time, by its topographical dimensions and its form, by its being the seat of a succession of ancient and recent events, by its memory.

Recomenda-se ao arquiteto visitar o local, o que não impede que arquitetura de não-lugares possa ser implantada no lugar. ${ }^{6} \mathrm{O}$ sítio em que será implantada a obra, ou a área de intervenção, deverá ser estudado segundo seis planos de análise. Cada um desses planos poderá ou deverá fornecer diretrizes de projeto a serem seguidas, ou mesmo a serem evitadas.

\subsection{Características topográficas}

A forma, as dimensões, a altimetria do sítio e a estrutura geológica do solo são todas elas elementos básicos do projeto. Esses aspectos, muitas vezes, sugerem soluções surpreendentes, como é o caso do Conjunto Habitacional do Pedregulho (1946), de Afonso Eduardo Reidy com seus "pilotis" no andar intermediário, devido ao acesso na encosta com forte declive, e a própria sinuosidade da edificação que acompanha elegantemente as curvas de nível da encosta.

\subsection{Orientação}

A trajetória solar, a orientação dos ventos dominantes, a direção das chuvas dominantes, as eventuais fontes de poluição sonora ou visual etc. são todas elas condicionantes externos sobre os quais é desnecessário enfatizar a importância. 


\subsection{Urbanismo}

As características espaciais do meio em que será inserida a intervenção arquitetônica/urbanística é de fundamental importância e devem ser cuidadosamente anotadas. Na malha urbana, deverão ser avaliadas as ruas tangenciais, a direção e intensidade do tráfego, as vias de acesso; localização das redes de infraestrutura urbana; marcos notáveis, monumentos, tendências de futuro desenvolvimento urbano; equipamentos tais como estações de metrô, paradas de ônibus, praças, jardins, iluminação pública, mobiliário urbano e outros. Da mesma maneira, no meio rural devem ser anotados os elementos característicos da área da intervenção.

\subsection{Paisagismo}

Anotações específicas devem ser feitas tendo em vista as características paisagísticas da área, tais como as áreas degradadas, a cobertura vegetal, os cursos d'água, as características do entorno visual e outras.

\subsection{Legislação urbanística, zoneamento}

A legislação urbana poderá limitar a volumetria da edificação e impor afastamentos que, por sua vez, determinam certas tipologias. Assim, estamos diante de definições fundamentais do projeto. Em Brasília, as Normas e Gabaritos (NGBs) determinam para cada situação a taxa de ocupação, a taxa de construção, a altura máxima e os afastamentos das edificações, além dos usos permitidos. Analisam-se também o Código de Edificações e o Plano Diretor, quando for o caso.

\subsection{Características históricoculturais}

Este é um aspecto mais sutil de ser abordado. Por vezes, o próprio sítio tem valores históricoculturais explícitos a serem considerados ou resgatados. Em Brasília, pode ser uma questão relacionada com o decreto de tombamento da cidade, ou da "revitalização" de áreas (caso do Concurso de Projetos para a Via W3, 2001). Às vezes, por motivos culturais, tornam-se desejáveis soluções imprevistas, como foi o caso do projeto do Restaurante Universitário da UnB 
(1971), o chamado Bandejão. Este autor considerou importante preservar as visuais ao Instituto Central de Ciências-ICC, conhecido como "Minhocão", projetado por Oscar Niemeyer (1961). Esse posicionamento básico determinou a transparência e a própria estética do prédio.

\section{Estudo de casos}

O estudo de projetos/obras semelhantes constitui um forte impulso para o entendimento do tema em pauta. A esse respeito Hélio Piñon (2000, p. 70) dá um passo além ao se referir ao conceito de cópia:

Durante o aprendizado escolar se trata, sobretudo de uma cópia reprodutiva, na qual a identificação de sistemas e critérios é a condição de reconhecimento do valor do edifício de referência [...] Superada a fase escolar, a cópia se converte em uma transcrição [...] Não creio que ninguém pense que o Concerto para Quatro Cravos, de J. S. Bach, tem menos valor musical pelo fato de ser uma transcrição literal de um concerto para quatro violinos de A. Vivaldi.

O estudo de casos guarda relação mais com a tipologia do que com a linguagem. Trata-se, tão somente, de avaliar o state-of-the-art. Novamente aqui vale repetir que não só a apreciação positiva é proveitosa. Saber o que evitar igualmente favorece a concepção.

\section{Estudos setoriais-croquis}

O objetivo aqui é o de possibilitar o entendimento espacial do PNA, não só em duas dimensões, mas, possível/desejável, em 3D. Este tópico refere-se ao estudo da(s) forma(s) adequada(s) e de suas dimensões, possíveis ou consagradas a cada uma das funções ou grupo de funções. Deve-se fazer uso intensivo de croquis setoriais em planta, corte e perspectivas. Trata-se de elaborar esquemas de funcionamento e interrelacionamento lógico das partes do PNA, por exemplo: o setor de administração; o setor de serviços; o setor de cozinha etc.

Em casos de elementos repetidos: o módulo do quarto de hotel, a sala de aula, a sala do edifício de escritórios, bem como as possibilidades de associação 
dos módulos. Nos casos singulares, a oficina, o laboratório, a sala de estudo em grupo etc. Nesta fase, poderá ser necessário definir a configuração de setores do projeto em termos de tipologias usuais ou desejadas, como seria o caso de um auditório, impondo grandes vãos. O mesmo vale para casos de repetições de um prédio modulado. Esses croquis são, tão somente, os elementos iniciais do entendimento espacial de um Programa que, por si, não impõem a solução definitiva do projeto, no entanto, possibilitam a compreensão da estrutura funcional/espacial dos ambientes. Um caso em foco é o projeto do Walt Disney Concert Hall (1997), Los Angeles, no qual o arquiteto Frank Gehry (1999) avaliou mais de 30 configurações da sala de concertos.

\section{Estudo de uso do solo - croquis}

Trata-se aqui de "zonear" o sítio ou o lote a ser ocupado, valendo-se dos elementos já elaborados no PNA, levando em consideração as características do lugar, as características dos estudos setoriais e os condicionantes externos. Quer dizer, distribuir o programa no terreno de maneira que se possa obter a melhor disposição das partes, ao mesmo tempo em que se evitam situações indesejáveis. Por exemplo: um setor requer silêncio, outro requer o aproveitamento de uma bela vista, um terceiro exige facilidades de acesso para carga/descarga etc. Essa fase é importante e deve ser vista como um conjunto de possibilidades espaciais, mas não constitui imposição definitiva ao projeto. No decorrer do desenvolvimento do estudo, outras (im)possibilidades podem sugerir disposições não previstas inicialmente. Trata-se aqui de criar situações ao invés de repetir soluções consagradas. O importante é registrar em croquis as situações desejáveis/indesejáveis, pois elas conduzem naturalmente a soluções de projeto. Os desenhos/croquis podem ser de vários tipos, abstratos ou manchas, mas é desejável trabalhar com as proporções relativas de áreas ou, até mesmo, em escalas aproximadas. Não se deve entender esse estudo como a invenção do partido-geral, o qual deverá sim conter esta análise, porém com ela não se confunde.

\section{0 estudo-preliminar, enfim}

Agora os "riscos" podem tomar seu curso e desenvolvimento, que englobam as questões conceituais, tendências de linguagem, uso de determinadas 
tecnologias, adequação social, adequação urbana, referências, metáforas, enfim, os Estudos Preliminares. Deve-se numerar a sequência desses estudos preliminares, registrando sua evolução, pois se trata de um processo iterativo, sendo o EP a versão final dessa fase, se é que podemos empregar a palavra "final".

Nessa fase, utilizamos o croqui como instrumento privilegiado de expressão, de exteriorização de nossas ideias para nós mesmos. Os croquis devem sempre abarcar a visão espacial do objeto de nossa concepção. Os croquis se expressam simultaneamente em três tempos: planta, corte e perspectiva; sempre juntos, não interessando a ordem em que são desenhados. Esse processo implica em repetições, ajustes, alterações e mudanças. Mas sempre em $3 \mathrm{~T}$ - três tempos.

\section{Uma palavra final}

Como já ficou claro, percebe-se que as primeiras definições, rabiscos e croquis, esboços formais de setores, e mesmo textos ou verbalizações já foram feitos nos momentos anteriores. Que fique claro: não se postula aqui a visão funcionalista de que o estudo-preliminar seja a decorrência unívoca da correta interpretação do Programa. Longe disso. O estudo-preliminar é uma síntese, uma kantiana ampliação do conhecimento, nunca uma dedução ou inferência lógica. O fato é que ao se adotar os procedimentos dos Estudos Iniciais, o processo da concepção arquitetônica não se depara com um vácuo de ideias, mas sim com um turbilhão de possibilidades já pressentidas e anotadas. O "vazio do papel em branco" rapidamente enche-se de traços coerentes, traços que têm significados, formas que têm nexo e objetividade. O projeto não inicia no estudo-preliminar, mas sim muito antes, como acima afirmamos.

\section{Initial studies in architectural designs}

\section{Abstract}

Young professional architects have a difficult time in the initial phase of a project. There is much angst on the transition from "Program" to the "Concept". 
We call it the "blank paper scare". In moderate doses this adrenaline is part of the creative process. At times however, this phase can turn complicated. Often the first drawings are unclear and disconnected from objectives of the project. As if by a touch of magic the sketches could provide the architectural answers to the questions posed by the project. In this article we suggest a series of procedures in which students and young professionals follow a more direct path towards the end result. On the contrary of what is being taught today, we seek to clarify that the concept of a project starts much earlier than the preliminary studies.

Keywords: Architectural conception. Preliminary study. Sketches.

\section{Referências}

AUGÉ, Marc. Non-Places: introduction to an anthropology of supermodernity. London: Verso Book, 1995.

GEHRY, Frank. Talks: architecture + process. New York: Rizoli International Publications, 1999.

MARTINEZ, Afonso Corona. Ensaio sobre o projeto. Brasília: Universidade de Brasília, 2000.

PIÑON, Helio. Ideia e forma. In: . Teoria do projeto. Porto Alegre: Livraria do Arquiteto, FAU/UFRGS, 2006.

ROSSI, Aldo. The architecture of the city: opposition books. Cambridge: The MIT Press, 1984. Chapter 3.

SCHÖN, Donald A. Educando o profissional reflexivo. [S.1.]: ARTMED, 2007. Cap. 7.

SILVA, Elvan. Sobre a renovação do conceito de projeto arquitetônico e sua didática. In: COMAS, Carlos (Org.). Projeto arquitetônico. São Paulo: Projeto, 1986.

TSCHUMI, Bernard. Architecture and disjunction. Cambridge: The MIT Press, 1994. 